\section{sciendo IMPACT OF THE ENGINE TUNING ON ITS TECHNICAL CONDITION ASSESSMENT BASED ON LIMITED NUMBER OF AVAILABLE PARAMETERS}

DOI 10.2478/ntpe-2018-0091

\author{
PhD. Eng. Marek Kutowicz \\ Polish Naval Academy in Gdynia, Poland
}

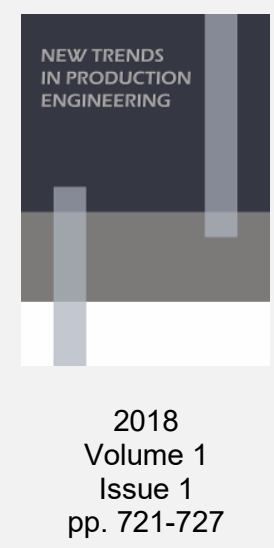

p. $721-727$

\begin{abstract}
Due to the limited scope of the diagnostic equipment on the ship, the technical condition of the engine is based on the measurement of pressure and temperature at the available measuring points. Usually it is the exhaust temperature at the outlet of individual cylinders, supercharging pressure, oil temperature and cooling water temperature. Sometimes the bearing temperature and turbocharger speed are also measured. Normally, if the engine is adapted to this, the maximum combustion pressure is measured periodically although distorted through the channels with the indicator valves. The paper presents examples of the exploitation of marine diesel engines, where there is a discrepancy between the actual technical state of the engine and the technical state of the engine based on the traditional diagnostic method based on a limited set of available parameters. These discrepancies resulted, inter alia, from the regular fuel injection timing and fuel dose adjustment, so that the measured parameters were adequate to the actual load of the engine. This adjustment is justified, but leads to masking engine components wear symptoms. In this situation, it can only be stated that the state of the fuel injection equipment is suitable for the current technical state of the some engine components and does not provide a sufficient basis for the extension of the repair interval.
\end{abstract}

Keywords: piston engine, indicated pressure, diagnostics

\title{
INTRODUCTION
}

In the process of the diesel engine exploitation, due to irreversible wear of the co-working elements, their structure degrades. Wear of each of the essential engine components causes that the engine can not to reach nominal performance, runs unevenly, and increases specific fuel consumption. By adjusting the engine, in particular the fuel injection system, the symptoms of unevenness in the load of the individual engine cylinders can be minimized without eliminating the cause.

The diagnostic equipment possessed by ship crews and shipyards repair crews is not adequate to carry out proper diagnostics that clearly identify the cause of the malfunction. In addition to the basic measuring equipment installed on the engine, ie. the supercharging pressure, fuel pressure, oil pressure and temperature at several critical points of the engine on each ship, there are portable pressure gauges indicators usually used by the crew to measure the maximum combustion pressure in the individual engine cylinders. The engine indication limited to measuring the maximum combustion pressure and the simultaneous measurement of the temperatures in the exhaust manifolds are the basis for adjusting the engines. Generally known rules determine when and how to change injection timing and fuel dosage in order to achieve equality of pressures and temperatures. Normally, with limited diagnostic measures, it is assumed that if the exhaust gas temperature and the maximum pressure in all cylinders are equal and adequate to the load condition, all engine components fulfill their function, engine is technically efficient and will remain in this condition for a long time.

This diagnosis is formally correct, as classification societies require only this to be included in the test report tables. But from a technical point of view, this diagnosis is naive, because generally the causes of malfunction can be divided into three main groups shown in Fig. 1. As long as the wear or contamination does not reach a critical value, the symptoms of wear and contamination can be masked by engine adjusting, but this can often lead to unreasonable prolonging of the engine repair period. 


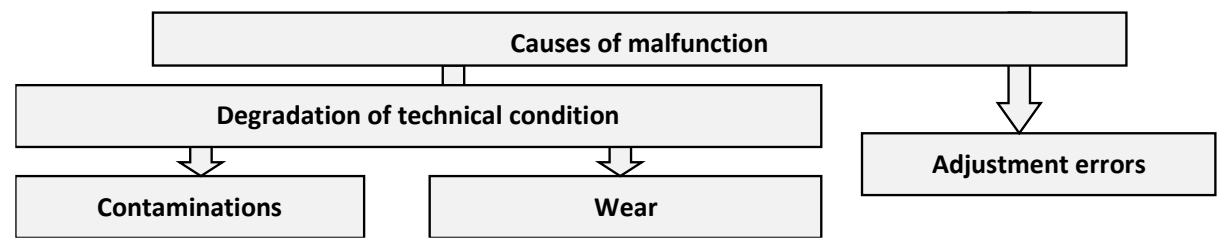

Fig. 1 General causes of engine failure

For all the machine parts and assemblies in which sliding friction occurs, such as precision injection pump pairs, injector nozzles and fuel pump camshafts, usually there are three wear periods (pre-wear period, normal wear rate period, and accelerated wear period). The first prewear period is the initial period of co-operation of elements in which the initial state of the surface layers of the lapped elements is transformed into an optimum state, characterized by increased wear resistance of these elements. Period II is characterized by constant wear intensity, which depends primarily on operating factors. Wear of the engine elements during this period usually leads to a minimal reduction in fuel consumption and an increase in ignition delay. During this period, minimal tuning adjustments are needed to compensate the effects of engine wear. In the third period there is accelerated wear, which means that the permissible clearances of the cooperating elements are exceeded. During this period equality of pressures and temperatures can be achieved, mainly at the significant expense of fuel injection acceleration and higher fuel doses. An engine operation in accelerated wear period will inevitably lead to failure. In practice, many cases have been identified where the registered exhaust temperatures were inadequate to the pressure inside the cylinder. This may indicate the wear of an important engine element. This element is not able to properly carry out its objective function and in that case further the engine adjustment may be harmful. It could be possible to achieve the expected equality of pressure and temperature in individual cylinders, but operating conditions, mechanical loads and thermal loads will deviate from expected and even acceptable. The fact of reaching the III period of operation can be stated by analyzing the trend line of various parameters. At the time of regulation, the trend line loses continuity and wear symptoms are masked. Then the forecast of further work of the engine will be too optimistic. Virtually every adjustment should start with a new trend line.

\section{DEGRADATION OF THE TECHNICAL CONDITION OF THE MARINE DIESEL ENGINE}

Analysis based on many years of diagnostic experience gathered at the Polish Naval Academy Institute of Ship Construction and Maintenance showed that the changes in the technical condition of the fuel injectors represent the largest part of engine malfunctions (Korczewski Z. et al.: 2000-2005).

As the engine ages, when the process of its operation approaches the working hour limit, the technical state of the engine depends on the wear of the components that create its work space. It manifests itself as loss of tightness, which results in worsening of cylinder charging and pressure drop in the compression stroke. Consequently, this leads to a reduction in maximum and mean indication pressure.

In a diesel engine, the loss of charge during compression while maintaining a constant fuel rate per cycle reduces the effective excess air ratio, what has an effect on the efficiency of the engine and the degree of smoke emission.

At the same time reduction in the weight of fresh charge causes a drop in temperature and pressure at the time of fuel injection. Reduction in pressure and temperature results in deterioration of the processes which occurred before fuel self-ignition and delay of self-ignition of fuel. In this situation most of the injected fuel is concentrated in large diameter droplets, which aggravates the conditions of its evaporation, increases the ignition delay and after burning process. Disturbances in combustion result in an increase in specific fuel oil consumption. Therefore, the engine does not achieve the rated parameters, even in spite of increased fuel consumption. 
If a leak occurs in the piston- piston ring -cylinder assembly it is usually accompanied by an increase in the lubricant oil consumption (Włodarski J. K., 2001). The engine wear process is continuous. Continued engine operation usually results in secondary damages that compromise engine reliability, shipping safety, and the environment. Exploiting the engine in degraded conditions, even if still possible, is also economically unjustified as the increase in operating costs due to increased fuel consumption and possibly lubricating oil may be greater than the cost of maintenance required.

\section{BRINGING MARINE DIESEL ENGINE BACK TO OPERATIONAL STATE}

Depending on the adopted operating strategy, after the specified working hours of operation, or after the occurrence of wear symptoms, the engine must be repaired to restore its technical condition of full operational parameters.

Engine repair primarily involves the verification, dismantling, regeneration and possibly replacement of selected engine components. The detailed scope of activities is usually determined by the engine documentation or operating instructions and is different for different types of engines. In the case of fuel injection equipment, repair usually involves the verification and regeneration or replacement and adjustment of injection pumps and injectors on the test bench, and after mounting the injection pumps on the engine on the geometric setting of the fuel discharge period. After performing the above operations, you can proceed to the dynamic control of the engine adjustment. During such an adjustment, only minor fuel dose adjustments and fuel injection advance angles are performed occasionally so that the maximum in-cylinder pressures and exhaust gas temperatures in all cylinder systems are equal (Piaseczny L., 1992). Maximum in-cylinder pressure depends on the compression pressure, fuel dose, and fuel injection advance angle. It can be assumed that this pressure increases as the values of the aforementioned values increase. For the given rotational speed, the maximum influence on the maximum pressure has an injection advance angle and therefore provides a basis for adjustment. Exhaust gas temperature under engine steady conditions depends, among other things, on the fuel dose per cycle, fuel injection advance angle and ignition delay. Furthermore, the temperature depends on the quality of the fuel and the quality of the resulting fuel/air mixture. In turn the susceptibility to ignition and combustion of this mixture depends on the proper functioning of the fuel injector. The algorithm for correct reliable engine adjustment is shown in Fig. 2.

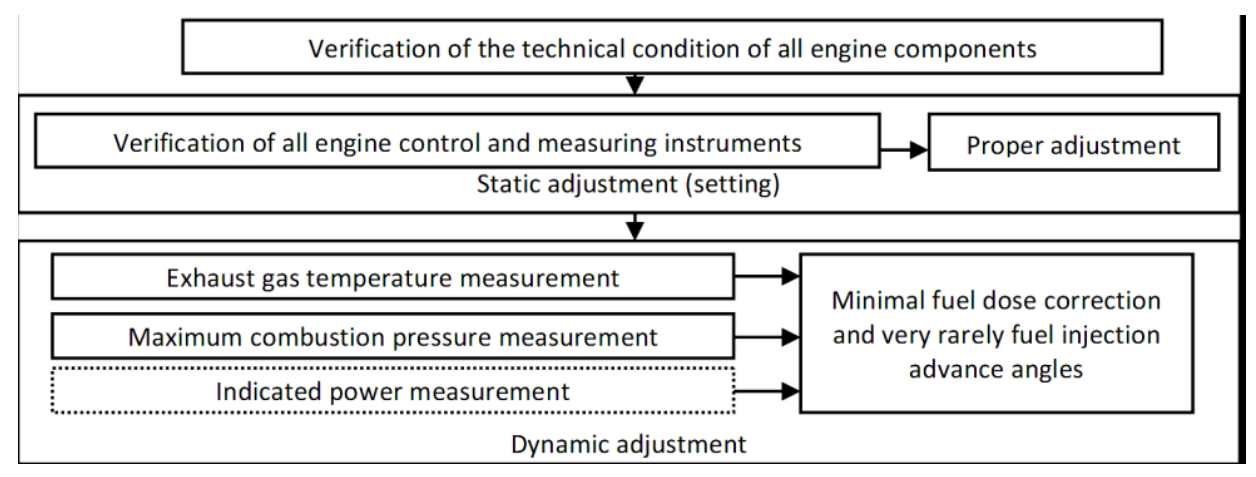

Fig. 2 The course of correct engine adjustment

The final stage of the engine repair is its delivery test in the presence of the shipowner. Tests are designed to verify the correct operation of the engine, especially in terms of fulfilling the safety requirements of shipping and as such result mainly from the provisions of the classification society. These tests should include measurement of the engine's performance parameters, such as, among other things, the measurement of the maximum power at which the limit values for any of the control parameters are not exceeded, the measurement of the fuel consumption and the uniformity of the load of the individual engine cylinders. In general, it is assumed that the variations in working process parameters, relative to the average values in individual cylinders, for nominal load and rotational speed should not be greater than (Piotrowski l., Witkowski K.: 2005):

- maximum combustion pressure of $\pm 3.5 \%$ 
- exhaust gas temperature $\pm 5 \%$.

A full range of tests can only be performed on the special stand with the dynamometer. Under real ship conditions, the engine power rating is practically unworkable because the ship is not equipped with and the engine test program is usually limited to measuring exhaust gas temperatures and maximum in-cylinder pressure. This would only be sufficient if the verification and static adjustment of all engine components was carried out in a reliable manner. In order to reduce repair costs, usually the engine verification is limited to only a few selected cylinder systems, and the static adjustment is omitted or superficial. In spite of this, when adjusting the start of fuel delivery angle and the fuel dose, it is possible to adjust the maximum internal pressures and exhaust gas temperatures from individual cylinders.

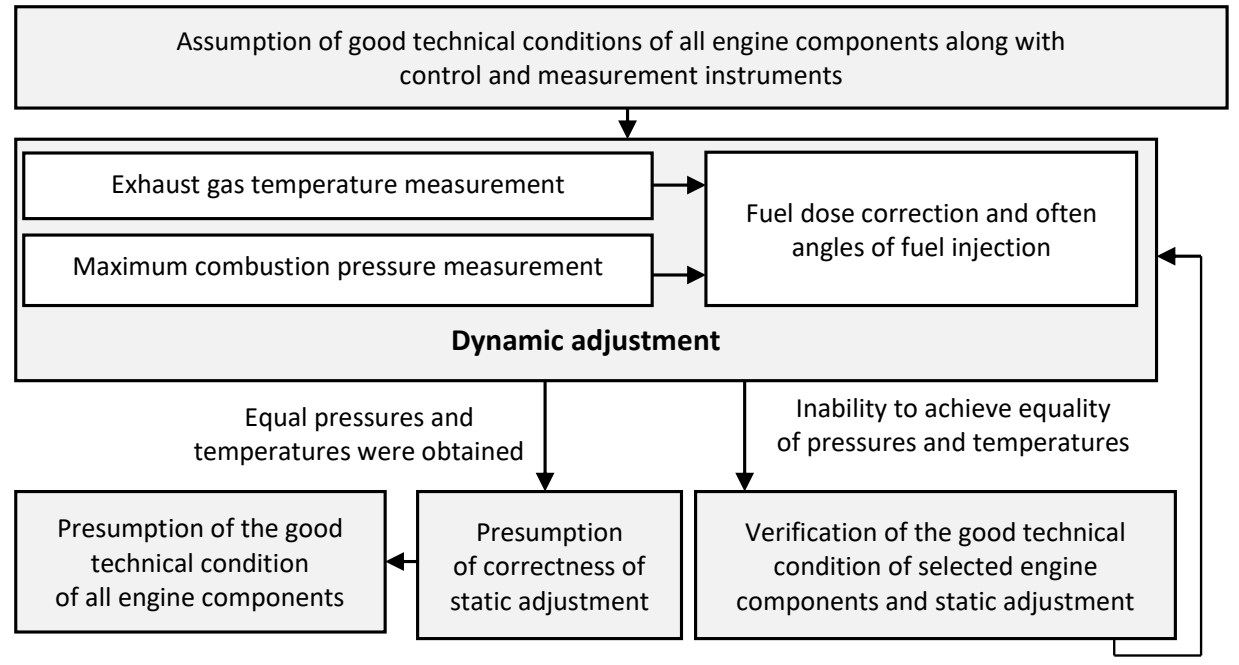

Fig. 3 The course of so called "economical" engine adjustment

Obtaining equality of maximum combustion pressures and temperature equations is a prerequisite for recognizing that engine repairs have been carried out correctly, but as shown by the examples given, this is not a sufficient condition, and often even the regulation of this criterion is detrimental to the engine. In practice, after changing the factory setting, the maximum pressure and exhaust temperature can no longer be diagnostic parameters for evaluating the engine's technical condition. Further operation of the engine adjusted in such way in the absence of other diagnostic methods is no longer a technical operation. Practically it is engine operation to failure.

Since 1992, the PNA diagnostic team has been involved in after-repair tests of engines on board Polish Navy ships. For this purpose, a Diagnostic Basis System has been developed, which is an integral part of a unique diagnostic method including an analysis of in-cylinder pressures and envelope of vibration signal in the crankshaft rotation angle domain (Korczewski Z. et al.: 20002005), (Łutowicz M., Wontka L.: 2006). This allows for a comparative statistical and factual analysis of the developed graphs and other figures characterizing the working processes in the engine cylinders. The parameters determined this way, such as the mean indication pressure, the indicated cylinder power, the maximum pressure inside the cylinder, the compression pressure in the cylinder, the speed of pressure rise inside the cylinder, etc., provide important information about the general state of fuel injection equipment setting. A significant addition to the parameters obtained from the pressure measurement is the use of the vibration signal generated by the injector needle and the intake and exhaust valves of the engine in diagnosing the valve gear mechanism (Lus T.: 2013). Since 2001 the methodology of diagnostic studies has been extended with additional endoscopic examinations (Łutowicz M., Wontka L.: 2006). This enabled the detection of engine adjustments made too hasty based on a limited set of available parameters. 


\section{CASE STUDY OF SO CALLED "CORRECT ENGINE ADJUSTMENT" FROM THE FORMAL POINT OF VIEW}

A case study of reduced compression pressure

In 1999, a routine regulation of 40DM type engines was performed on one of the 912M type ships. During the dynamic adjustment on the engine described, a slight correction of the fuel doses on the two cylinders was made to compensate the maximum combustion pressures and exhaust outlet temperatures of the individual engine cylinders.

After adjustment, the maximum temperatures deviation between the cylinders does not exceed $70^{\circ} \mathrm{C}$ while the manufacturer allows deviations of up to $100^{\circ} \mathrm{C}$.

The highest exhaust gas temperature was noted on cylinder 4 on the left cylinder block. The unevenness of maximum combustion pressures did not exceed $\pm 3.5 \%$. Engine adjustment was considered satisfactory and even without objections. The only shortcoming was the poorly audible metallic sound of an unknown source of origin. As this sound did not go away, after about two months of operation of the engine it was decided to carry out diagnostics of the engine based on the Polish Naval Academy apparatus and team. Diagnostic tests revealed unbelievable damage to the engine under test. It has been found that on the cylinder 4 there is a considerably lower value of compression pressure (Fig. 4), with average value of maximum combustion pressure. The cause of this state of affairs was one of the four outlet valves of this cylinder which was not closing. The valve closed only when the piston approached the TDC and hit the valve. This was the reason for the metallic sound mentioned before. By contrast, because of the lower compression pressures and thus the lower pressure at end of compression, the fuel needed more time to evaporate and self-ignite. However, when it was self-igniting, it combustion process had knocking characteristic and caused maximum combustion pressure which did not deviate from the average value of the remaining engine cylinders (Figure 4).

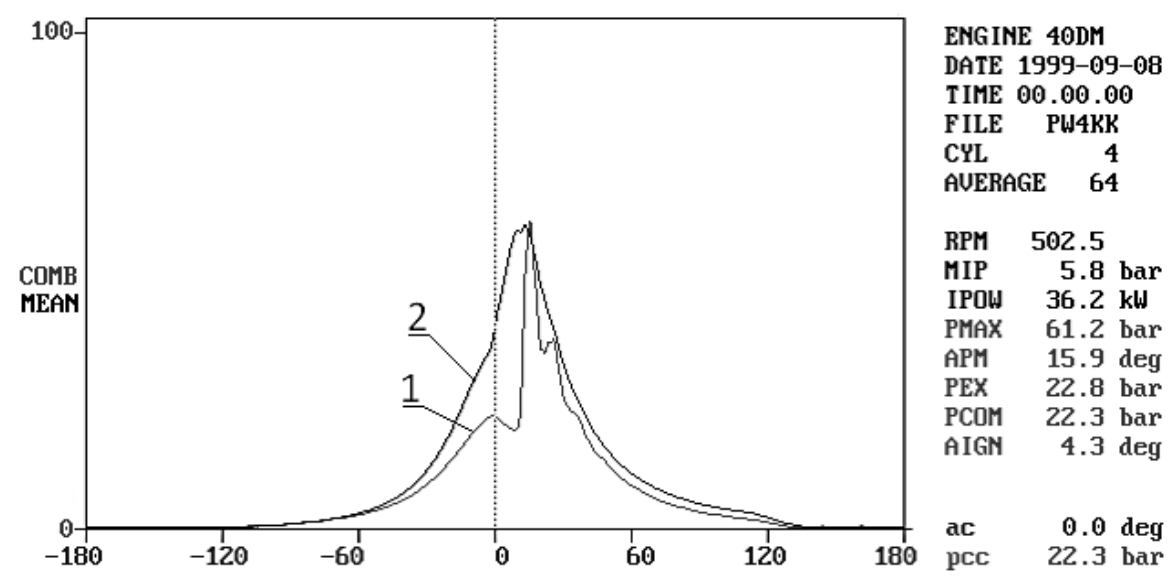

Fig. 4 Indication pressure versus angle of the crankshaft rotation of the engine in cylinder No. 4 (graph 1) and versus the average internal pressure of the remaining cylinders

Source: (Łutowicz M., Wontka L.: 2006) of the engine (graph 2)

I quote this case despite the fact that it comes from 18 years ago because it is the best to illustrate the discussed research problem. It was an inspiration to carry out much work to seek new diagnostic methods and to supplement old methods with new elements. This case could have been unequivocally diagnosed with the means available if the fuel supply to the cylinder No. 4 was switched off and the compression pressure was measured.

\section{A case study of wear of precision parts of fuel injection pump}

As a result of the wear, there is a clearance between the cylinder and the pump plunger and the rounding of the control edges. As a result of leakage, the dose of injected fuel is reduced, and as a result of the rounding of the control edges, the injection is delayed and shortened. This results in lowering the maximum pressure and reducing the exhaust gas temperature in the 
spent pump cylinder and increasing the exhaust gas temperature in the remaining cylinders. This is one of the main failures detected by the Polish Naval Academy diagnostic team.

As an example, the results of the diagnosis of the Sulzer engine type 8AL20/24 on one of the ships are cited. The measurements were made before engine maintenance work. The goal of the measurement was to defining the scope of the engine repair. Measurements after engine repair were made in order to verify the repair result. Prior to repairs, approximately $10 \%$ lower cylinder pressure in cylinder No. 2 was observed than in the remaining cylinders and exhaust gas temperature was lower about $50^{\circ} \mathrm{C}$. The result of the comparison of the indicated pressure and the envelope of vibration acceleration in cylinder 2 (red and blue) against the results of the most representative cylinder 5 (black) is shown in Figure 5.

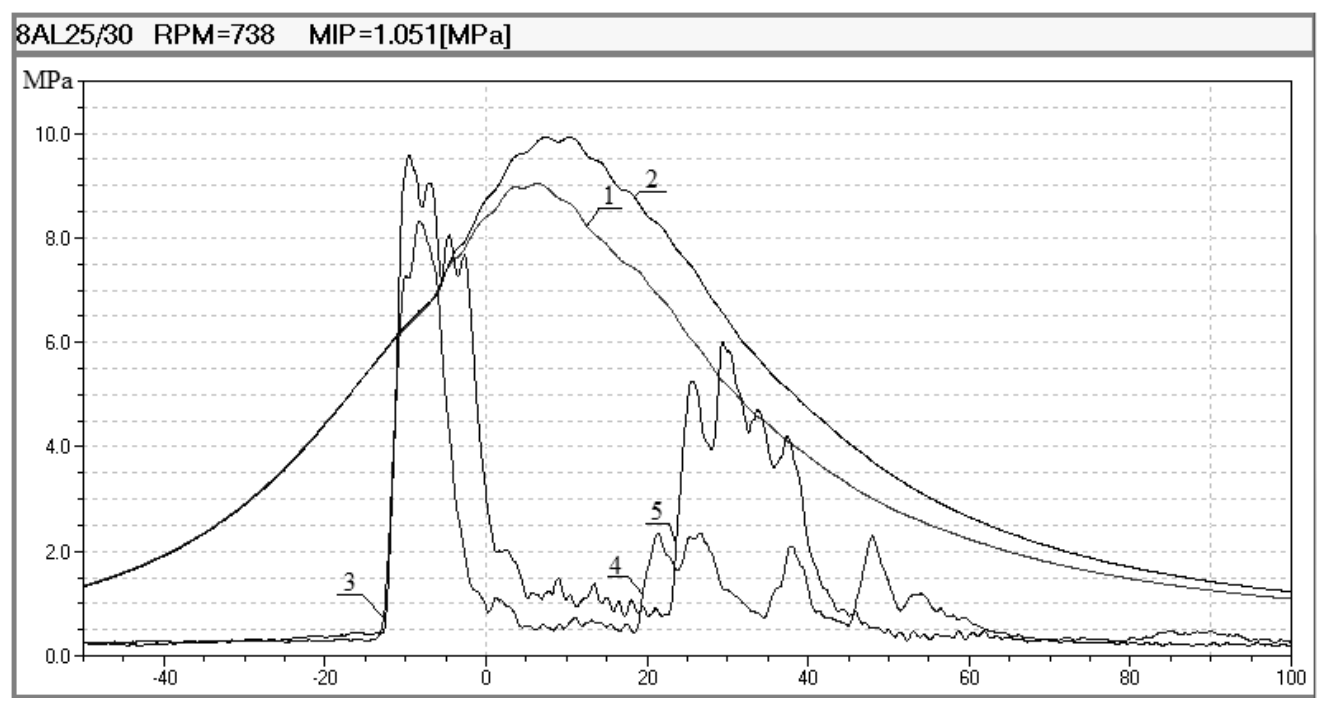

Fig. 5 Indication pressure and envelope vibration acceleration recorded in cylinders 2 and 5 prior to repairs. 1 - pressure in cylinder 2, 2 - pressure in cylinder 5, 3 - injection start in cylinder 2 and 5,4 - end of injection in cylinder 2.5 - end of injection in cylinder 5.

An analysis of the envelope of vibration was made at the beginning and end of the injection. Exact the same as in the cylinder 5 injection start does not provide an adequate pressure increase. Ignition timing indicates correct operation of the injector. The reason for the reduced pressure is probably the wear out of precision parts in the fuel pump. It was recommended to exchange it. The results of the verification measurements in identical conditions after engine repair are shown in Figure 6 . It was found that after replacing the pump, the fuel dose was increased. The temperature of the exhaust gases increased, but the max pressure remained low. By accelerating the injection, the maximum pressure was increased to the desired value. Formally, the technical condition of this cylinder system does not raise any objection that the injection pump has reached its final wear. The wear condition can be determined by analyzing the combustion pressure and vibration envelope, which show a significant injection advance and an inadequate pressure increase. Such a condition would be acceptable as an ad hoc solution but not as a repair result. 


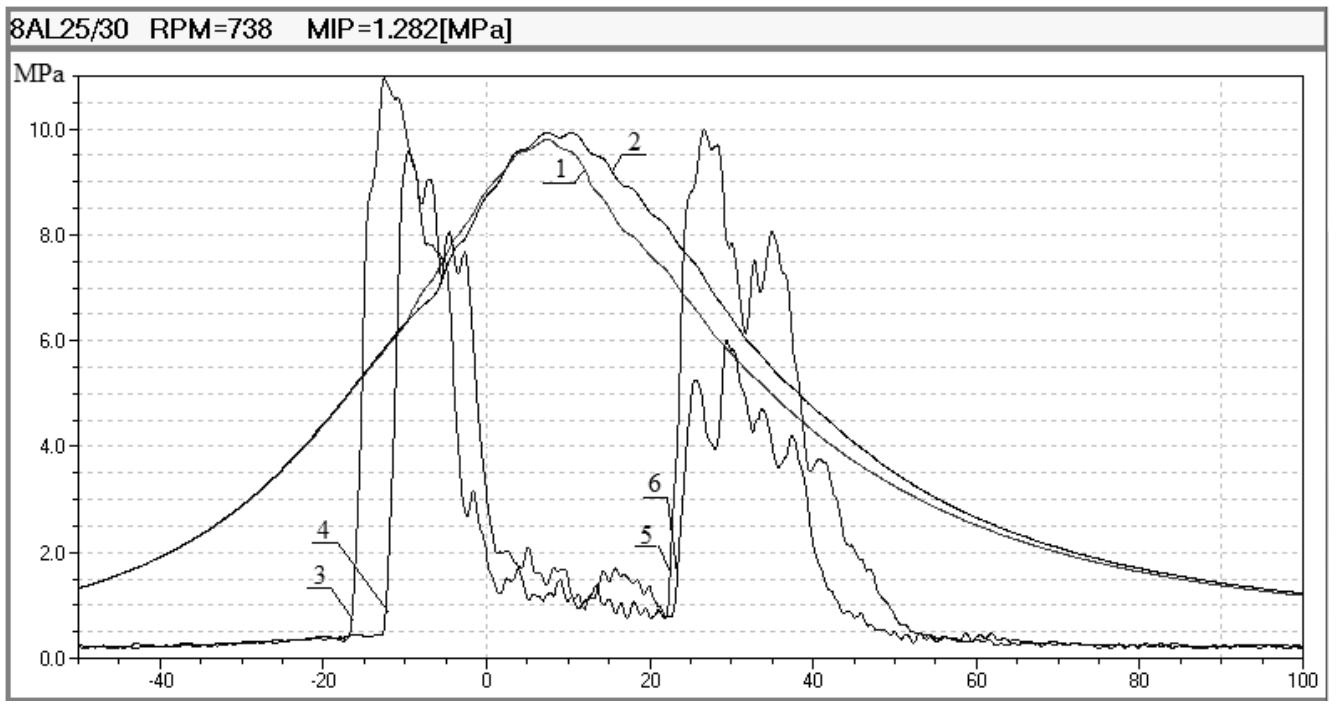

Fig. 6 Indication pressure and envelope vibration acceleration recorded in cylinders 2 and 5 after engine repairs. 1 - pressure in cylinder 2, 2 - pressure in cylinder 5, 3- start injection cylinder 2, 4 - start injection cylinder 5, 5 - end of injection cylinder 2, 6 - end of injection cylinder 5.

A case study of distortion of the indicated pressure curve by the loose indicating valve closing disc

Very common in Sulzer engines type $A$ is damage of the indicator valve. The loose valve disc acts as a check valve. This does not affect the engine's operation, but prevents it from performing the correct indication. In the example shown in Figure 7, the damaged indicator valve deforms the pressure waveform.

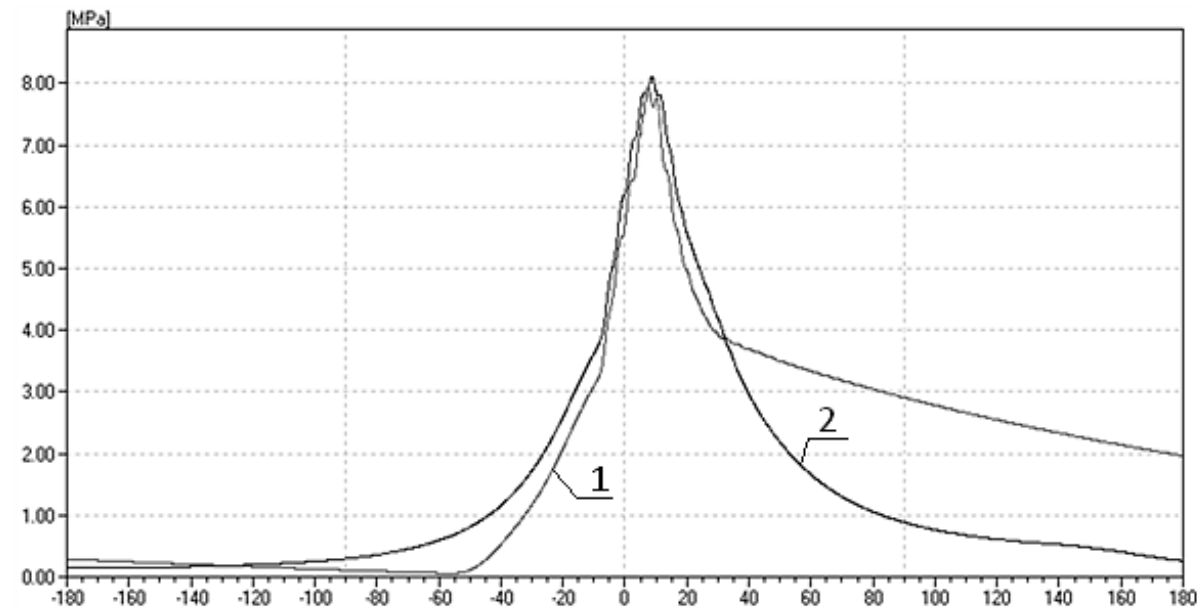

Fig. 7 Indication pressure versus angle of the crankshaft rotation. 1. deformed by defective valve, 2 . average of remaining cylinders.

The reading value of the maximum pressure was understated by cutting the lower part of the graph. Faith in the indication of the electronic maxi meter gauge without analyzing the pressure curve has led the crew to adjust the engine. As a result of this regulation, the actual maximum pressure was exceeded. Formally, the desired adjustment effect was obtained. This error will not occur with the use of a mechanical indicator, which regardless of type measures the actual maximum pressure. The electronic instrument practically measures the difference between maximum and minimum pressure, and is very sensitive to the indicator valves damage and to the resulting deformation of the lower part of the indicative pressure curve. 


\section{CONCLUSIONS}

Ship engines must comply with classification society regulations - shipbuilding regulations and marine classification. The rules specify the ways of assessing the condition. Compliance means that the engine is in good technical condition only in formal terms.

Practically, the diagnosis based only on the maximum combustion pressure and exhaust temperature is incomplete and does not provide any basis for assessing the technical condition of the engine and in particular for extending the repair interval.

The engine indication cannot be limited to measuring the maximum pressure to make any sense, it must be preceded by an inspection of the injectors at the test bench and confirmed by other diagnostic methods.

Testing of the relationship between the vibration envelope and the indicated pressure enables the technical condition assessment of the engine fuel equipment.

Unrecognized diagnostic methods that could undermine this evaluation, need to be first recognized by classification societies, what greatly hampers progress in the development of ship diagnostics.

\section{REFERENCES}

Korczewski Z. et al.: (2000-2005). Reports on diagnostic tests of piston-engine diesel engines operated on MW RP ships. Research works AMW, Gdynia.

Lus T.: (2013). Tests results of new diagnostic method for WOLA marine diesel engines type $\mathrm{H}$. Journal of KONES Powertrain and Transport, Vol. 20, No. 1, Warszawa.

Łutowicz M., Wontka L.: (2006). Selected cases of incorrect regulation of marine piston engine based on traditional methods of assessing its technical condition, Selected problems of designing and operating of shipyard, University of Szczecin, Szczecin.

Piaseczny L., (1992). Marine engine repair technology. Wydawnictwo Morskie, Gdańsk.

Piotrowski I., Witkowski K.: (2005). Exploitation of marine diesel engines: Foundation for the Development of the Maritime School in Gdynia, Gdynia.

Włodarski J. K., (2001). Operating States of Marine Combustion Engines. Foundation for the Development of the Maritime School in Gdynia. 